\title{
Study on the Creep and Fracture Evolution Mechanism of Rock Mass with Weak Interlayers
}

\author{
Na Zhao $\mathbb{D}^{1,2}$ Yibin Zhang $\mathbb{D},{ }^{2}$ Haibin Miao, ${ }^{1}$ and Lixin Meng $\mathbb{D}^{2}$ \\ ${ }^{1}$ State Key Laboratory of Coal Mine Safety Technology China Coal Technology \& Engineering Group Shenyang Research Institute, \\ Shenfu Demonstration Zone, Shenyang 110000, China \\ ${ }^{2}$ College of Mechanics and Engineering, Liaoning Technical University, Fuxin 123000, China
}

Correspondence should be addressed to Na Zhao; zhaona24@163.com

Received 21 November 2021; Revised 11 January 2022; Accepted 19 January 2022; Published 10 February 2022

Academic Editor: Hiroshi Yoshihara

Copyright $\odot 2022 \mathrm{Na}$ Zhao et al. This is an open access article distributed under the Creative Commons Attribution License, which permits unrestricted use, distribution, and reproduction in any medium, provided the original work is properly cited.

\begin{abstract}
To study the influence of weak interlayers on the creep failure characteristics of rock masses, based on the continuous-discontinuous method (CDEM), the uniaxial compression creep experiments of rock masses containing weak layers were numerically simulated; and the weakened rock masses under different conditions were analyzed in detail. We focused on the final failure mode and creep curve of the rock mass with a weak interlayer $\left(\boldsymbol{\theta}=30^{\circ}, \boldsymbol{d}=20 \mathrm{~mm}, \boldsymbol{c}=1\right)$ as examples by selecting the crack distribution state of the model during compression at different time steps. We analyzed the propagation and convergence mode of cracks in a rock mass with weak layers. The research results show that the existence of weak interlayers affects the integrity of the rock mass and the creep failure mode. With the increase in the inclination of the weak interlayer, the failure mode of the rock mass changes from shear failure through the weak layer to slip along the weak layer. For shear failure, the total strain and steady-state creep rate of the rock mass first decrease and then increase, showing a U-shaped distribution; as the thickness of the weak interlayer increases, the rock mass always follows the shear in the weak layer. Creep failure occurs on the fracture surface, and the total strain and steady-state creep rate of the rock mass are positively correlated with the thickness. If the thickness continues to increase, there is no significant difference in the creep characteristics of the rock mass; the volume occupied by the soft rock in the body increases, the overall rigidity of the rock mass decreases, and the plastic deformation increases. The form of creep failure of the rock mass changes from sliding shear failure along the weak layer to sliding shear failure through the weak interlayer. The total strain and steady-state creep rate of the rock mass increase with the increase in the number of weak layers; the greater the distance between the weak layers, the smaller the total strain and steady-state creep rate of the rock mass. The slower the crack growth rate, the less likely the rock mass to undergo creep damage.
\end{abstract}

\section{Introduction}

The weak layered rock mass is a natural layered material composed of single rocks of different thicknesses, different inclination angles, and different mineral components. The weak layered rock mass is one of the common types of rock masses in rock engineering, along with construction, mines, slopes, and tunnels [1]. The rock mass with a weak interlayer has both the characteristics of strength anisotropy and the transverse isotropy of layered rock mass deformation, so its mechanical properties are complex [2]. Numerous engineering practices have shown that the creep characteristics of rock masses with weak layers are one of the important reasons for the deformation and instability of the engineering. The long-term stability of these rock projects has always been the focus of attention [3-5]. Therefore, researching the creep characteristics of rock masses with weak interlayers has important theoretical guiding significance.

At present, the research on rock masses with weak layers usually adopts methods such as laboratory experiments [6-9], numerical simulation [10-12], and theoretical analysis $[13,14]$. In terms of theoretical research, Jaeger [15] first proposed a transverse isotropy criterion with a single weakface rock mass as the research object and then regarded the internal cohesive force in the Mohr-Coulomb criterion as a 
function of the layer dip angle. The internal friction force is taken as a constant, and the shear strength formula of the layered rock mass is given and revised. Saroglou et al. [16] and Singh et al. [17] applied the revised Mohr-Coulomb criterion and Hoek-Brown failure criterion to layered rock masses based on predecessors. Zienkiewicz et al. studied the mechanical properties of composite rock masses, proposed a simple multilayered rock mass model, and considered the viscoplastic strain rate of the rock mass as the sum of the contributions of each joint group and rock material. The applicability of these methods to the mechanical properties of composite rock mass has not yet been verified. In terms of physical experiments, because of the limitations of on-site sampling of rock masses containing weak layers and sample processing, it is difficult to conduct indoor experiments on real raw rock materials. Therefore, many scholars use similar materials to prepare rock masses containing weak layers $[18,19]$ and conduct corresponding research. Because the rock mass with weak layers is an anisotropic, discontinuous, heterogeneous, and random natural aggregate, similar simulation results often differ greatly from the real situation. To better conduct indoor experimental research on layered rock masses, scholars have proposed a new production method $[20,21]$ using epoxy resin glue or marble glue as a binder and using different types of original rocks, cutting, grinding, bonding, and assembling to make a layered rock mass sample with controllable mechanical properties and inclination of the weak layer. This method is simple to operate for similar simulation experiments, and the sample production cycle is short, which can reflect the macromechanical properties of the layered rock mass but cannot reflect the real interface bonding in the layered rock mass.

Many scholars have studied the strength characteristics and creep characteristics of rock masses containing weak layers. Xu [22] and others used similar materials to make layered rock masses with weak interlayers and conducted triaxial rheological tests on them to study the rheological deformation laws and accelerated rheological characteristics of layered rock masses with weak interlayers. Xiong et al. [23] used PFC2D to numerically simulate the triaxial compression experiment of layered rock mass and studied the influence of the inclination angle of the interlayer rock mass on the strength of the rock mass under triaxial compression load and the law of crack development and failure mode. Li [24] conducted compression and triaxial compression experiments on the salt rock mass with mudstone interlayers and determined that the mudstone interlayer has a significant impact on the deformation and failure characteristics of the salt rock mass. Huang et al. [25] simulated the excavation process of a tunnel with a weak interlayer using a combination of physical test model and numerical analysis. The results indicated that the position, inclination, and thickness of the weak interlayer are important factors affecting the stability of the tunnel.

Most of the above studies simplified the rock mass containing weak layers into an equivalent homogeneous and transversely isotropic composite material for analysis. The research direction focuses primarily on the location and dip angle of weak layers under different confining pressures. The influence of rock mass strength, deformation characteristics, and stability and some new failure criteria and stability evaluation methods for rock masses containing weak layers have been established; and some new progress has been made. However, previous studies mostly analyze the mechanical properties and failure modes of rock masses containing weak layers under uniaxial or triaxial compression from a macro perspective and do not consider the macroand mesoscopic evolution process of the creep fracture of rock masses containing weak layers.

This article is based on the continuous-discontinuous element method (CDEM), and in it, we establish and solve the creep fracture geometric model of a rock mass with weak interlayers. The fracture process of rock mass with different weak interlayer conditions was numerically simulated using crack initiation, propagation, and connection to penetration. We analyzed the evolution of crack propagation in a rock mass with weak interlayers in each creep stage. The effects of different dip angles of weak interlayers, thickness of weak interlayers, and the number of weak interlayers and spacing of weak interlayers on the final failure mode and creep fracture of the rock mass. The creep rupture evolution mechanism of a rock mass with weak interlayers was given. It provided a theoretical basis for preventing and controlling the creep disaster of a rock mass with weak interlayers.

\section{The Evolution Law of Unit Failure}

2.1. Basic Concepts of CDEM. CDEM can be defined as a dynamic explicit solution algorithm based on breakable elements under the Lagrangian system. Strict control equations are established through the Lagrangian energy system, and the dynamic relaxation method is used to display an iterative solution, which realizes a continuousdiscontinuous unified description. It can simulate the entire process of material from continuous deformation to fracture to movement, combining continuous and discrete calculations. The advantages of calculation include the finite element, finite volume, and spring element methods for continuous calculation and the discrete element method for discrete calculation.

The numerical model of CDEM can be divided into a block part and an interface part, as shown in Figure 1. The block part comprises one or more finite elements, which are used to characterize the continuous deformation characteristics of the material; and the interface part is the contact surface of the block boundary. Introducing a breakable, onedimensional spring on the boundary of the block will lead to cracks in the material.

2.2. Discrete Element Calculation of CDEM. In CDEM, the key to switching from finite element to discrete element calculation is to perform discrete element calculation at the boundary of the block. The spring system model of the interface is shown in Figure 2.

In the failure calculation, the criterion for interface failure is based on the maximum tensile stress and the 

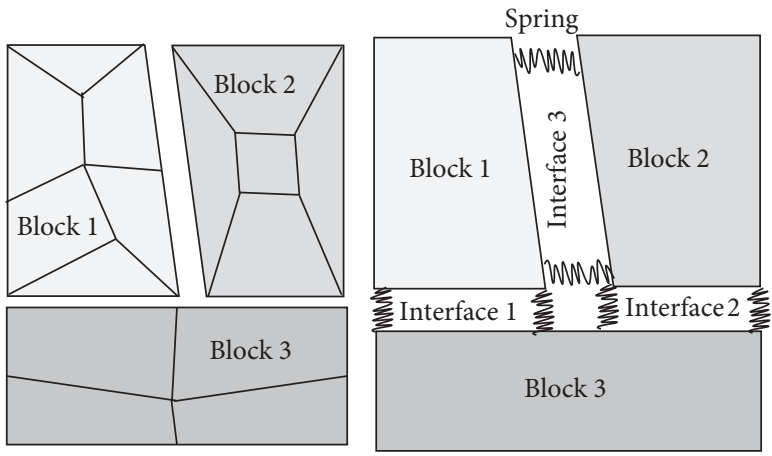

FIgURE 1: The block and interface parts of CDEM.

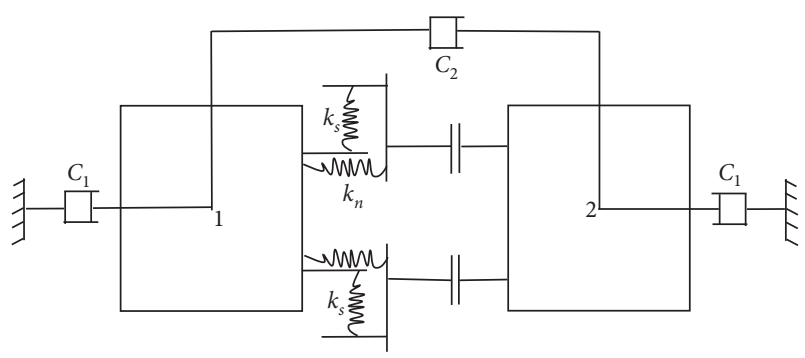

Figure 2: Discontinuous calculation model.

Mohr-Coulomb composite criterion, divided into tensile failure and shear failure.

When the interface is under tensile failure, as shown in Figure 3, the interface contact spring adopts the maximum tensile stress criterion; and the interface force state is shown in the following equation. The tensile force after failure and the force on the node are both zero.

$$
\sigma_{t}= \begin{cases}k_{n} u & \left(\sigma<\sigma_{t}\right), \\ 0 & \left(\sigma \geq \sigma_{t}\right),\end{cases}
$$

where $\sigma_{t}$ is the tensile strength of the contact surface, $k_{n}$ is the normal stiffness of the spring, and $u$ is the normal displacement.

When the interface is under shear failure, as shown in Figure 4, the interface contact spring adopts the Mohr-Coulomb criterion; the interface force state is as shown in the following equation:

$$
\tau= \begin{cases}k_{s} v & (|\tau|<c-\sigma \tan \varphi), \\ \operatorname{sign}(\dot{v}) \sigma_{n} \tan \varphi & (|\tau| \geq c-\sigma \tan \varphi),\end{cases}
$$

In the formula, $k_{\mathrm{s}}$ is the tangential stiffness of the spring, $v$ is the tangential displacement, $c$ is the contact cohesion, $\varphi$ is the contact internal friction angle, and $\sigma_{n}$ is the normal stress.

2.3. Feasibility Analysis of CDEM. In recent years, many scholars have used the discrete element method to simulate the propagation process of rock cracks, analyze the rock fracture mechanism, and verify the feasibility of this method for simulating rocks by comparing it with the laboratory experiment data [26-29]. In this section, CDEM was used to

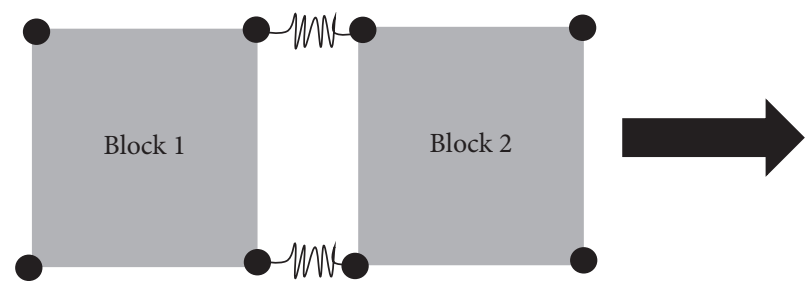

Figure 3: Tensile failure mode.

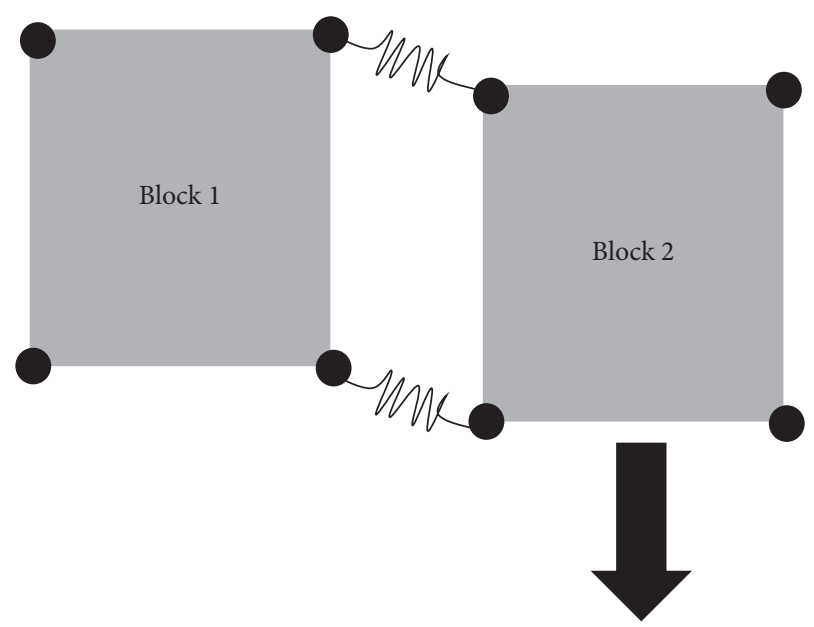

FIgURE 4: Shear failure mode.

simulate a rock mass with prefabricated fractures under uniaxial compression. The fracture dip angles were $0^{\circ}, 30^{\circ}$, $45^{\circ}$, and $60^{\circ}$, respectively. We compared the simulation results with the DEM experiment and laboratory experiment results adopted by Jiang [30] to verify the feasibility and applicability of CDEM.

Table 1 shows the failure patterns of samples with prefabricated cracks simulated by the CDEM experiment, DEM experiment, and laboratory experiment, respectively. Specific parameter selection and other details have been listed in this article [30]. This section only lists the results to verify the feasibility of CDEM.

The CDEM simulated crack growth pattern is similar to the DEM and laboratory experiments, and obvious wing crack growth can be observed. The initial crack develops in the direction of principal stress. The test results prove the applicability of CDEM to simulate rock. In the following section, we used CDEM to simulate the crack propagation mode of a rock mass with weak interlayers under different working conditions.

\section{Numerical Model and Research Plan of Rock Mass with Weak Layers}

This numerical model uses a two-dimensional plane stress model with a model size of $50 \mathrm{~mm} \times 100 \mathrm{~mm}$. As shown in Figure 5 , the inclination angle of the weak interlayer is $\theta$, the thickness is $h$, the number of weak layers is $c$, and the interlayer spacing is $d$. The interface contact between layers is completely elastic regardless of the influence of 
TABLE 1: Comparison of failure modes of CDEM experiment, DEM experiment, and laboratory experiment.

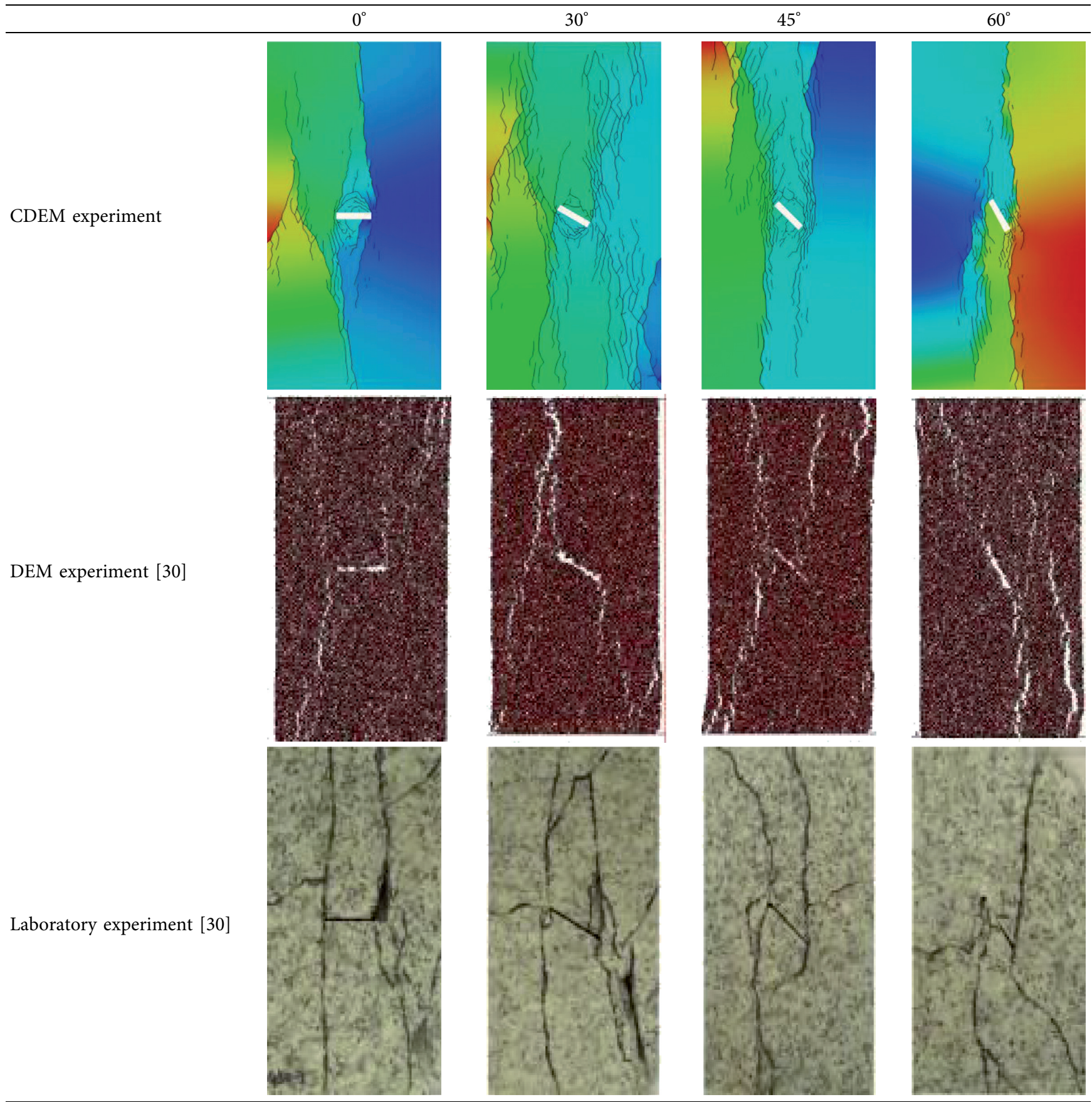

self-weight and the rigid constraints between the upper and lower end faces of the specimen and the indenter. The vertical displacement is constrained at the bottom of the model, and the vertical pressure $\boldsymbol{F}$ is applied at the top of the model. The model uses all triangular isoparametric elements. The calculation model is divided into 12,644 triangular elements and 5,784 nodes. The element model adopts the Mohr-Coulomb ideal elastoplastic model, and the element contact surface is set to the Mohr-Coulomb model, considering strain softening. We conducted conventional uniaxial compression creep simulation experiments on each group of rock masses containing weak layers. At the same time, a monitoring point was set at the midpoint of the top of the model to record the relevant parameters of the model to analyze its deformation and failure laws.

Based on the comparative analysis of laboratory experiments and the collected data, the basic physical and mechanical parameters in the numerical model are shown in Table 2. The numerical calculation is based on the occurrence of a through-sliding failure surface in the model or the nonconvergence of the calculation as the end condition. 


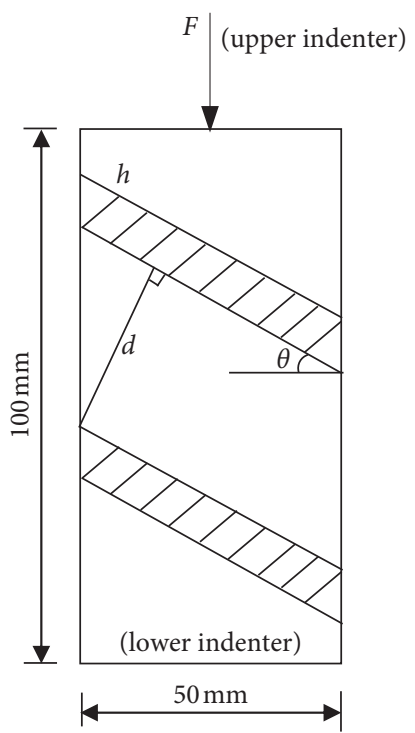

(a)

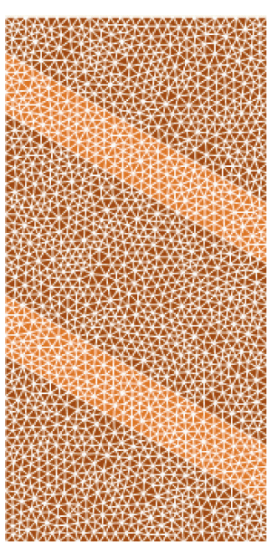

(b)

Figure 5: Schematic diagram of uniaxial compression $\left(\theta=30^{\circ}, d=30 \mathrm{~mm}, c=2\right)$. (a) Geometrically loaded model. (b) Numerical calculation model.

TABLE 2: Basic mechanical parameters of numerical model.

\begin{tabular}{lcccccc}
\hline Lithology & Density $/\left(\mathrm{kg} / \mathrm{m}^{3}\right)$ & Elastic modulus/(GPA) & Poisson's ratio & Cohesion/(MPa) & $\begin{array}{c}\text { Tensile strength/(MPa) } \\
\text { Internal friction } \\
\text { angle } /\left({ }^{\circ}\right)\end{array}$ \\
\hline Hard rock & 2,000 & 5 & 0.25 & 0.4 & 0.2 & 35 \\
Soft rock & 1,800 & 1 & 0.15 & 0.3 & 0.15 & 30 \\
\hline
\end{tabular}

To avoid the influence of the complex bonding mechanical parameters of the interface on the numerical results, the calculation process does not consider the effect of structural surfaces between adjacent rock masses. It is assumed that the bonding between the rock masses is good [31]. To explore the uniaxial compression values under different conditions and simulate the law of strength characteristics and the creep mechanical behavior of a rock mass with weak layers, we considered the influence of the four main factors of the inclination angle, thickness, number of layers, and the distance between weak interlayers on the creep mechanical behavior of the rock mass, as shown in Table 3, the numerical simulation program.

\section{Analysis of Numerical Simulation Results}

4.1. Crack Propagation Evolution Process. The numerical model of a rock mass with weak interlayers is composed of many elements, and the element boundary is connected by springs. Under constant pressure, tensile failure and shear failure occur when the interface contact spring reaches the maximum tensile stress and Mohr-Coulomb composite criterion. We took a rock mass with weak interlayers $\left(\theta=30^{\circ}\right.$, $d=20 \mathrm{~mm}, c=1)$ as the research object to analyze the crack propagation path. In the simulation process, the initiation position, quantity, length, and propagation direction of the initial crack can be observed intuitively, and the initial state diagram and final state diagram in the deceleration creep stage, isokinetic creep stage, and accelerated creep stage can be intercepted. By comparing the front and rear pictures, we analyzed the initiation position and propagation path of a tensile crack and shear crack. This method is used to describe the crack evolution process in the creep process of rock mass with weak interlayers, wherein the direction indicated by the red arrow in the figure is the crack propagation direction.

As shown in Figure 6, at the moment the load is applied, the initial pores and cracks inside the model are compressed and closed, the model undergoes instantaneous elastic deformation, and no cracks are generated on the surface of the model. For tensile crack $a$ and shear crack $b$, the length of crack $a$ and $b$ is about $1 \mathrm{~mm}$. The extension direction of tensile crack $a$ is perpendicular to the interface of soft and hard rock mass, and the shear crack $b$ extends along the direction of the weak layer. When it runs to 2,600 , new cracks $(c, d, e, f, g, h, j)$ continue to sprout in the weak layer, and the propagation direction of shear cracks $c, e$, and $h$ is consistent with the direction of crack $b$. The propagation direction of extension cracks $d, f$, and $j$ is the same as the direction of crack $a$, the propagation direction of shear crack $g$ is opposite to crack $a$, the extension crack $d$ extends toward the lower interface, and a wing crack develops on the left side of extension crack $j$. When it gets to time Step 7,600, it enters the stage of constant velocity creep. The lower end of the shear crack $c$ expands in an " $S$ " shape along with the 
TABLE 3: Numerical simulation scheme of uniaxial compression of carbonaceous slate.

\begin{tabular}{lr}
\hline Influencing factors & Test group \\
\hline Sandwich inclination $/\left(^{\circ}\right)$ & $0,15,30,45$ \\
Sandwich thickness/mm & $10,20,30,40$ \\
Number of mezzanine layers & $1,2,3$ \\
Interlayer spacing/mm & $10,20,30$ \\
\hline
\end{tabular}
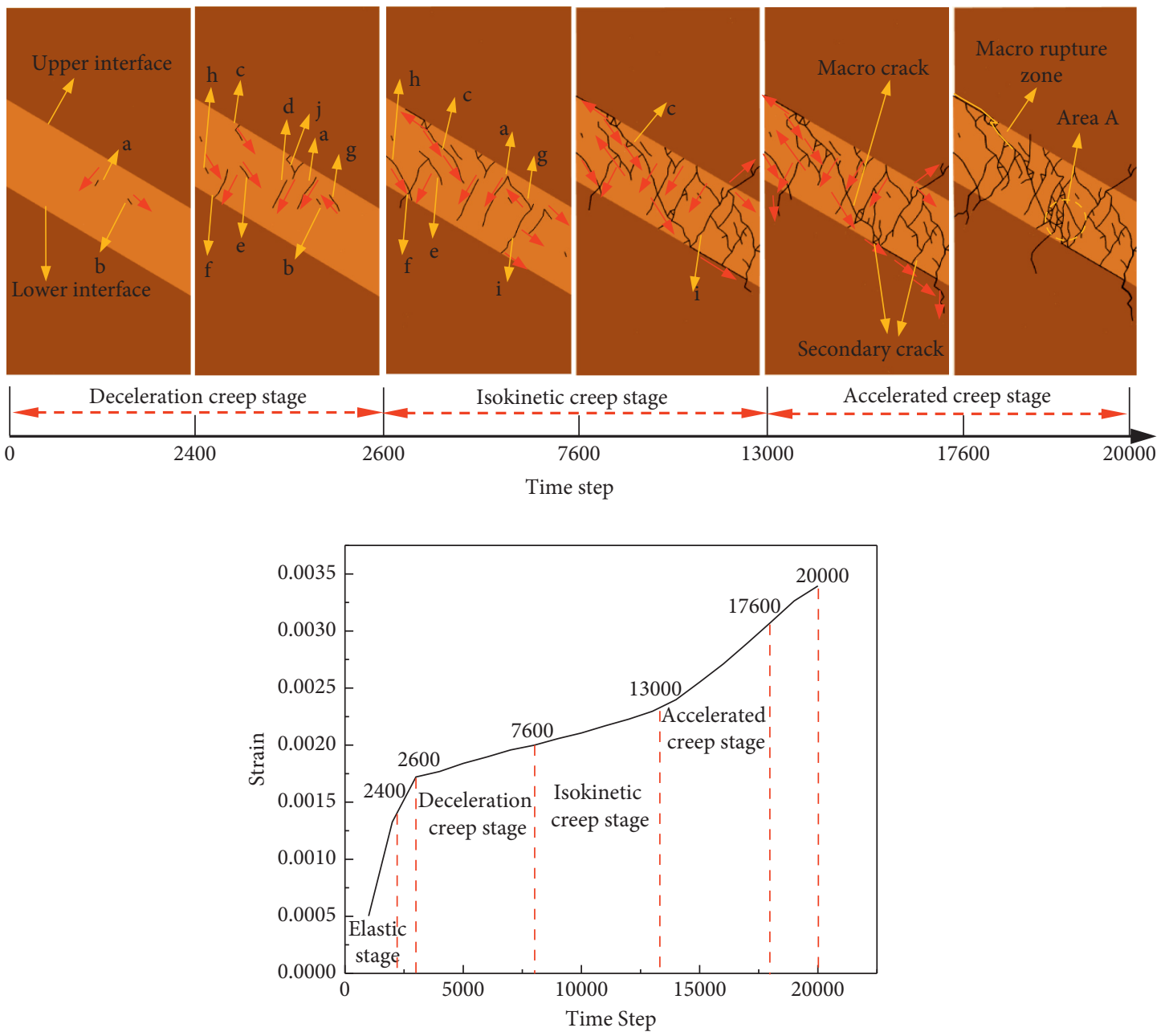

FIgURE 6: Model crack growth evolution process and creep curve $\left(\theta=30^{\circ}, h=20 \mathrm{~mm}, c=1\right)$.

direction of the weak layer, and the upper end of the crack $c$ expands straight upward along the upper interface and shear crack $h$. Toward the lower interface, it expands and extends in an arc shape. The tensile crack $f$ intersects shear cracks $e$ and $h$ at a point, and shear crack $g$ extends along the upper end of the weak layer, converges with tensile crack $a$, and forms a line perpendicular to crack $g$. The new tensile crack $i$ extends downward and extends to the lower interface. Because the bonding strength at the interface is lower than the strength of the rock mass, at this point, crack $i$ expands along the lower interface with lesser strength and intersects with shear crack $c$. The formation of macroscopic cracks and the accumulation of damage within the model under long-term load results in the continuous initiation of secondary cracks in area A. In addition, the secondary cracks converge, develop, and evolve along the tips of the macroscopic cracks. In the process of crack propagation and evolution, most of the cracks in the weak layer grow in a single direction. With increasing time, the cracks gradually extend, converge, and intersect, showing an overall change law of "basically unchanged-small growth-large surge" [32]. Some units (area A) at the weak layer of the model were broken, causing macroscopic cracks to form a macroscopic rupture zone; and the model suffered shear slip failure along the rupture zone.

4.2. The Influence of Weak Layer Dip on the Creep Characteristics of Rock Mass. To explore the influence of weak interlayer inclination angles $\left(\theta=0^{\circ}, 15^{\circ}, 30^{\circ}, 45^{\circ}\right)$ on the creep failure of rock masses containing weak layers, we conducted 
a test under given conditions $(c=1, h=20 \mathrm{~mm})$. Numerical simulations were conducted on the sample, and the crack propagation morphological characteristics and equivalent displacement cloud diagrams of weak layers with different dip angles are shown in Figure 7.

Under constant load conditions, when the weak layer inclination angle is $\theta=0^{\circ}$, the main mode of cracks is shear cracks. After the shear cracks develop to a certain extent, X-type conjugate shear failure occurs through the weak interlayer. When the inclination angle of the weak layer is $\theta=15^{\circ}$, the shear cracks first extend along the direction of the weak layer and then extend through the interlayer along the loading direction, finally showing a shear slip failure trend. When the inclination angle of the weak layer is $\theta=30^{\circ}$, the sample has a shear fracture at the interface, and sliding shear failure occurs along the interlayer direction. When the inclination angle of the weak layer is $\theta=45^{\circ}$, the sample undergoes sliding shear failure along the weak interlayer. With the increase of the inclination angle, the failure form of the rock sample with the weak layer changes from the shear failure through the weak layer to the slip shear failure along with the weak layer.

The creep curves of rock masses with different weak layer dip angles are shown in Figure 8. When the weak layer dip angle is $\theta=0^{\circ}$ and $15^{\circ}$, the creep curves of the rock mass with weak layers only show the decelerating creep stage and the constant velocity creep stage. When the dip angle of the weak layer continues to increase, the rock mass gradually shows three stages of complete creep. First, in the elastic compaction stage, the pores and cracks inside the rock mass are compressed and closed at the moment of load application, and zero or very few shear cracks appear on the surface of the sample. After entering the deceleration creep stage, the strain of the rock mass increases slowly, but the creep rate gradually decreases. The change in the weak layer inclination has no obvious effect on the deformation of the rock mass. The strain of each rock mass at this stage is about $1.63 \times 10^{-3}$. In the stage of constant velocity creep, the creep rate of each group of rock mass remains stable, and the steady-state creep rate $v_{c p}$ of the rock mass with weak layer dip angles $\left(\theta=0^{\circ}, 15^{\circ}, 30^{\circ}, 45^{\circ}\right)$ is $4.32 \times 10^{-8}, 9.88 \times 10^{-9}, 7.12 \times 10^{-8}$, and $1.56 \times 10^{-7}$, respectively. The initial cracks inside the rock mass continue to develop and expand, and many secondary cracks evolve during this stage. Under the long-term action of external force, the cracks continue to evolve, extend, and intersect one another to form a penetrating slip surface. The rock mass has undergone significant macroscopic deformation by this point, and the total strain $\varepsilon$ of the rock mass is $0.0024,0.0020,0.0034$, and 0.0070 in sequence. As shown in Figure 9, the dip angle of the weak layer is one of the factors that affect the creep of the rock mass. In the range of small dip angles, the creep strain and creep rate decrease with the increase in the dip angle of the weak layer. Beyond this range, the strain increases with the increase of the dip angle of the weak layer, which conforms to the U-shaped distribution characteristics.
4.3. The Influence of the Thickness of the Weak Layer on the Creep Characteristics of Rock Mass. To deeply study the influence of the thickness of the weak interlayer $(h=10 \mathrm{~mm}$, $20 \mathrm{~mm}, 30 \mathrm{~mm}, 40 \mathrm{~mm}$ ) on the creep characteristics of the weak layered rock mass under a constant load and a given working condition $\left(\theta=30^{\circ}, c=1\right)$, numerical simulation calculations were conducted on the samples. The crack propagation characteristics and equivalent displacement cloud diagrams of the rock masses with different weak layer thicknesses are shown in Figure 10.

Under constant load conditions, the failure of the rock mass with weak layers starts from the weak layer and then gradually expands to the hard rock on both sides. When the thickness of the weak layer is $h=10 \mathrm{~mm}$, the cracks in the weak layer are mainly shear cracks, and the rock mass tends to slide along the rock formation. When the thickness of the weak layer is $h=20 \mathrm{~mm}$, shear fracture occurs in the weak layer, and the sample runs along the weak layer. The layer has shear slip failure when the thickness of the weak layer is $h=30 \mathrm{~mm}$ and $40 \mathrm{~mm}$. Local shear failure occurs on the lower left side of the weak layer, and the sample slips along the shear surface. The four failure modes of weak layercontaining rock masses with weak layer thickness always result in sliding shear failure along the weak layer shear failure surface.

Under the same working conditions, the creep curves of each weak layer of thick rock mass are shown in Figure 11. The figure indicates that the creep curves of the weak layer thickness, $h=30 \mathrm{~mm}$ and $h=40 \mathrm{~mm}$, have similar trends. When a constant load is applied, the instantaneous strains of the rock mass with weak layers $(h=10 \mathrm{~mm}, 20 \mathrm{~mm}, 30 \mathrm{~mm}$, $40 \mathrm{~mm})$ are $5.02 \times 10^{-4}, 5.08 \times 10^{-4}, 5.11 \times 10^{-4}$, and $5.29 \times 10^{-4}$, respectively. At this stage, the initial pores and cracks inside the rock mass are closed. After entering the deceleration creep stage, the internal cracks of the rock mass gradually begin to develop and expand. The creep curve indicates that the thickness of the weak layer gradually influences the deformation and failure trend of the rock mass. In the constant velocity creep stage, the steady-state creep rate $v_{c p}$ of each rock mass is $1.12 \times 10^{-8}, 7.27 \times 10^{-8}$, $1.99 \times 10^{-7}$, and $2.01 \times 10^{-7}$ in sequence. After entering the accelerated creep stage, the cracks are connected and penetrated; and a shear fracture surface appears inside the weak layer. The rock eventually creeps and fails. The total strain $\boldsymbol{\varepsilon}$ of the rock mass with different weak layer thicknesses is $0.0019,0.0034,0.0054$, and 0.0055 . Figure 12 indicates that as the thickness of the weak interlayer increases, the creep rate and creep strain of the rock mass gradually increase as well, and the rock mass is more prone to instability failure. Under long-term load, the thickness of the weak interlayer has an important influence on the creep deformation of the rock mass.

\subsection{The Influence of the Number of Weak Layers on the Creep} Characteristics of a Rock Mass. Previous studies have examined the influence of the dip angle and thickness of the weak layer on the creep rupture of a rock mass containing a single weak layer, and it can be determined that the creep 

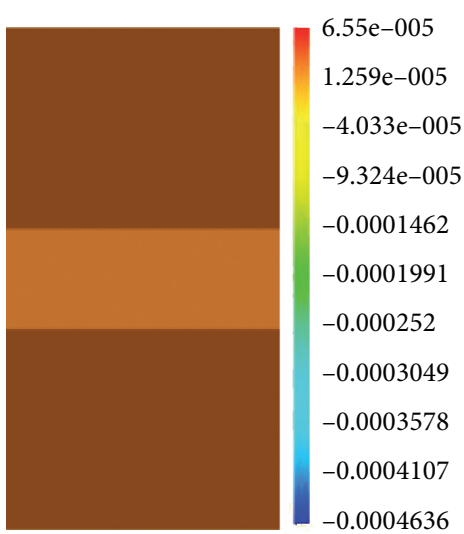

(a)
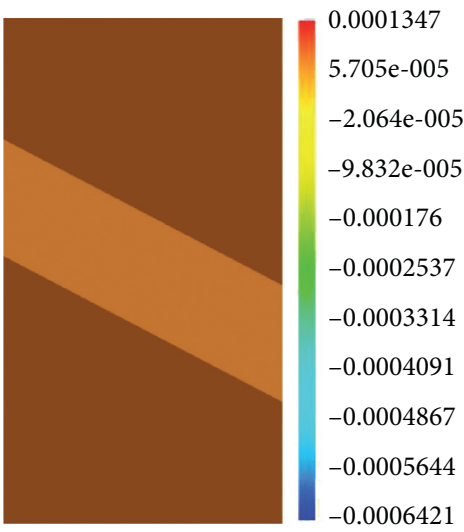

(c)
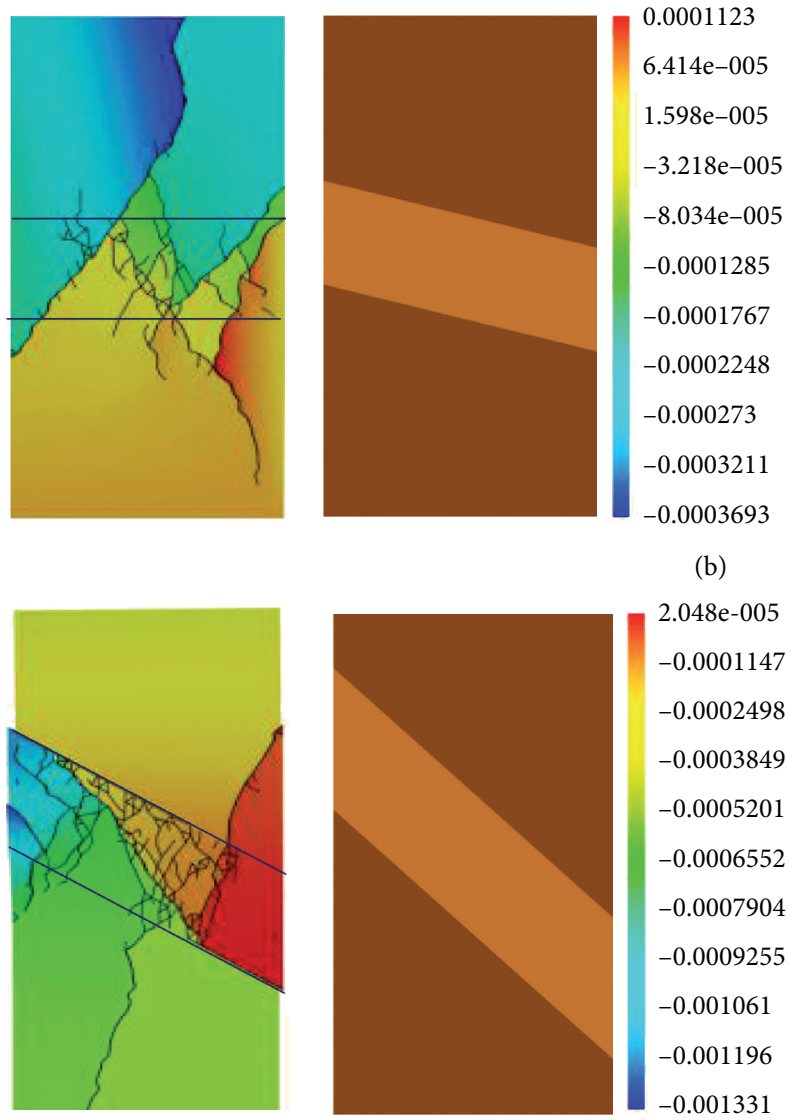

(b)
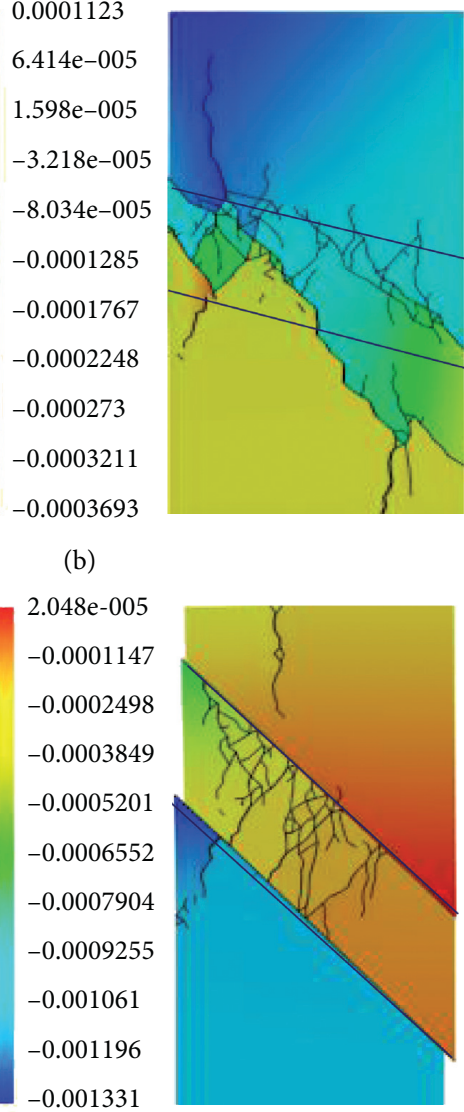

(d)

Figure 7: Nephogram of rock mass and equivalent displacement with different dip angles of weak layer. (a) $\theta=0^{\circ}$. (b) $\theta=15^{\circ}$. (c) $\theta=30^{\circ}$. (d) $\theta=45^{\circ}$.

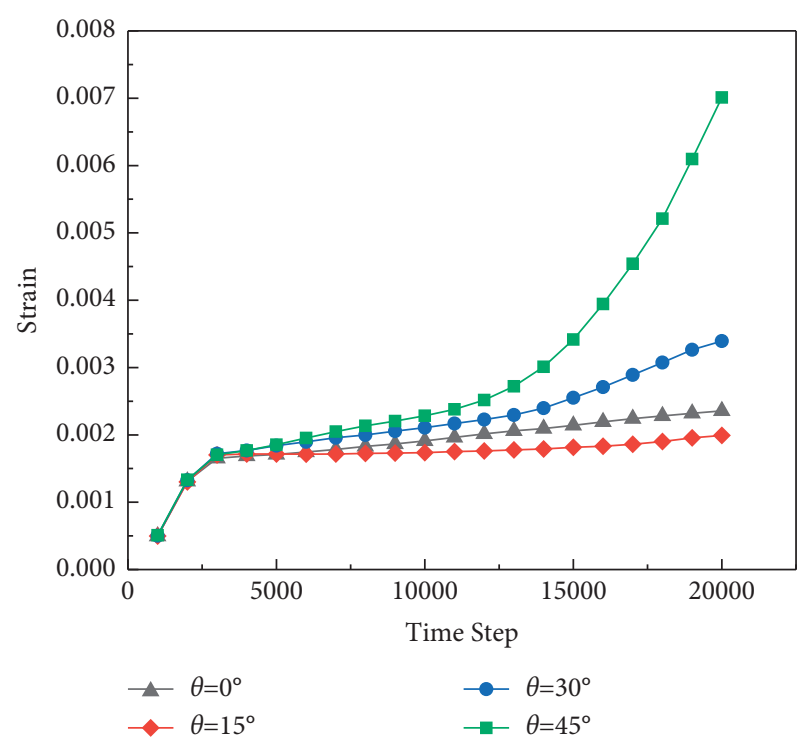

FIGURE 8: Creep curves of rock masses with different dip angles of weak layers.

curve of a rock mass containing a single weak layer is similar to the creep curve of a complete rock mass. But under the same inclination angle, thickness, and a different number of

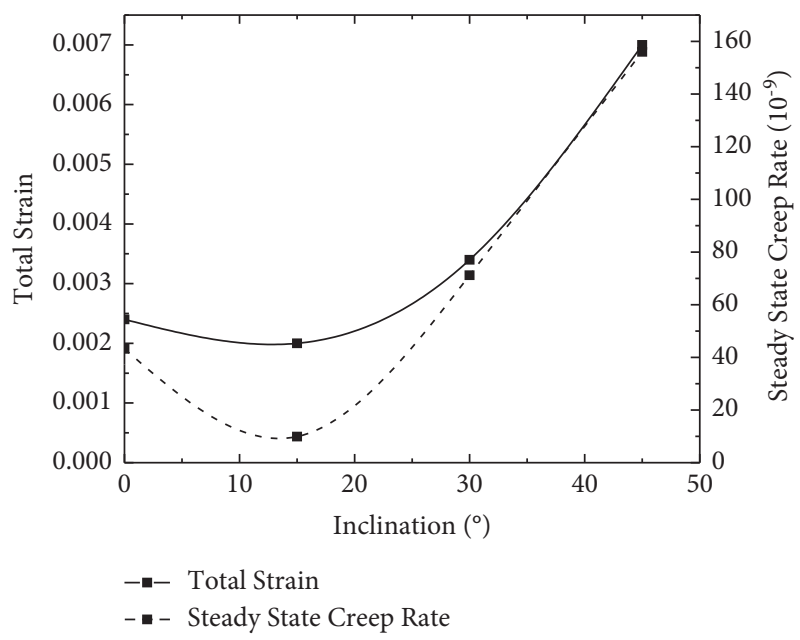

FIgURE 9: Total strain and steady creep rate of rock mass with different dip angles.

layers, how do the creep rupture mode and creep curve change? This section will add two sets of samples with different weak layer numbers, $c=2$ and $c=3$, and explore the effect of changes in the number of weak layers on rock mass creep under the same working conditions $\left(\theta=30^{\circ}\right.$, 


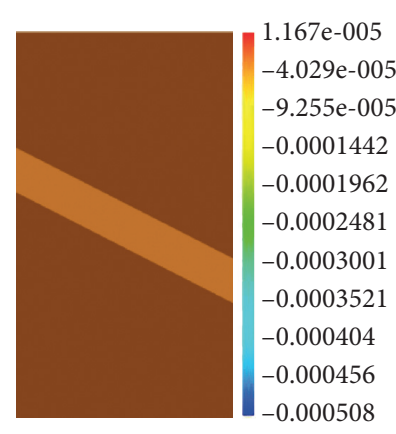

(a)
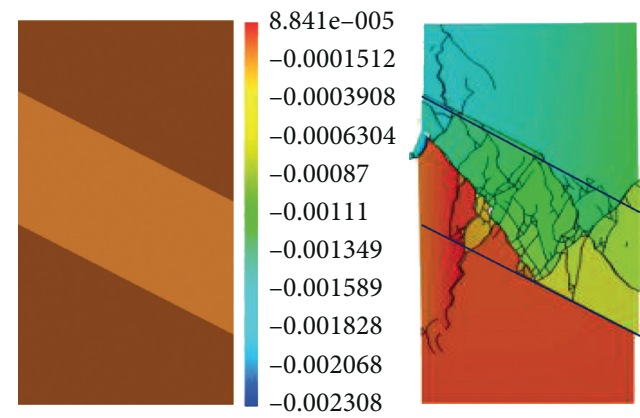

(c)
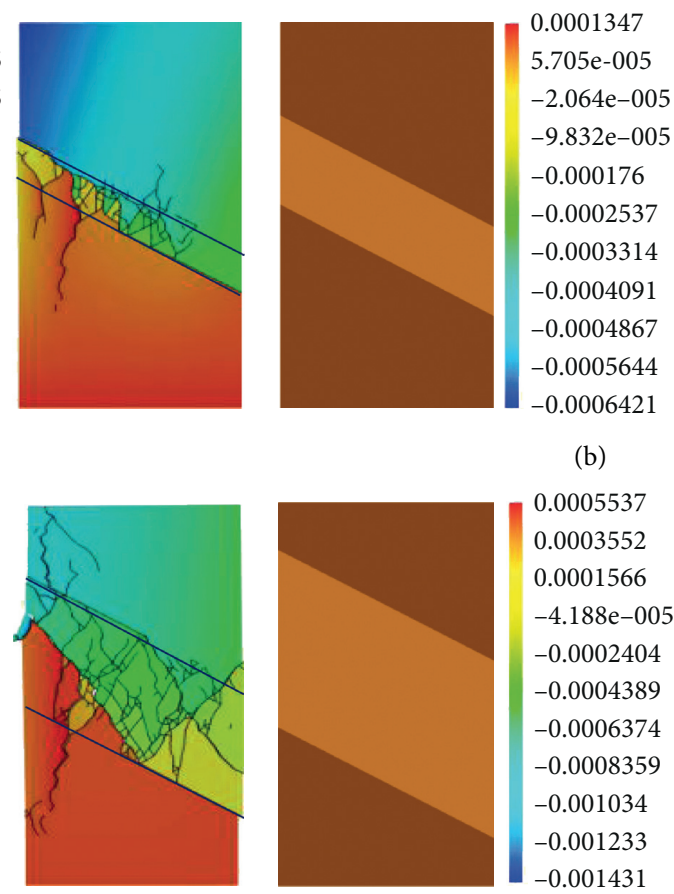

(b)
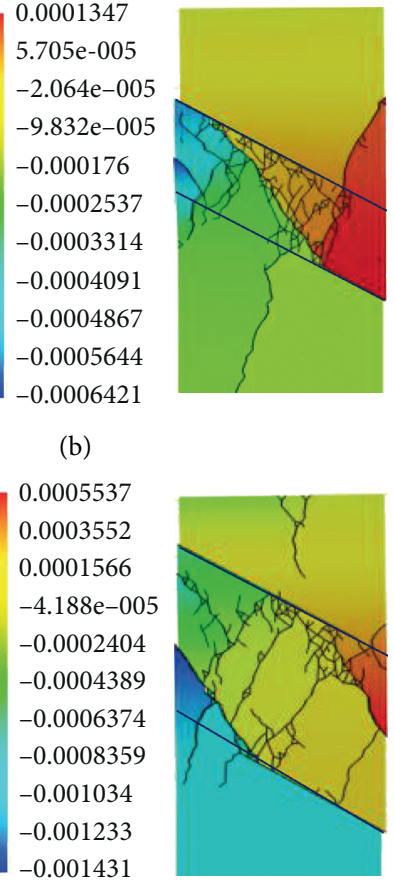

(d)

FIGURE 10: Rock mass with different weak layer thickness and equivalent displacement nephogram. (a) $h=10 \mathrm{~mm}$. (b) $h=20 \mathrm{~mm}$. (c) $h=30 \mathrm{~mm}$. (d) $h=40 \mathrm{~mm}$.

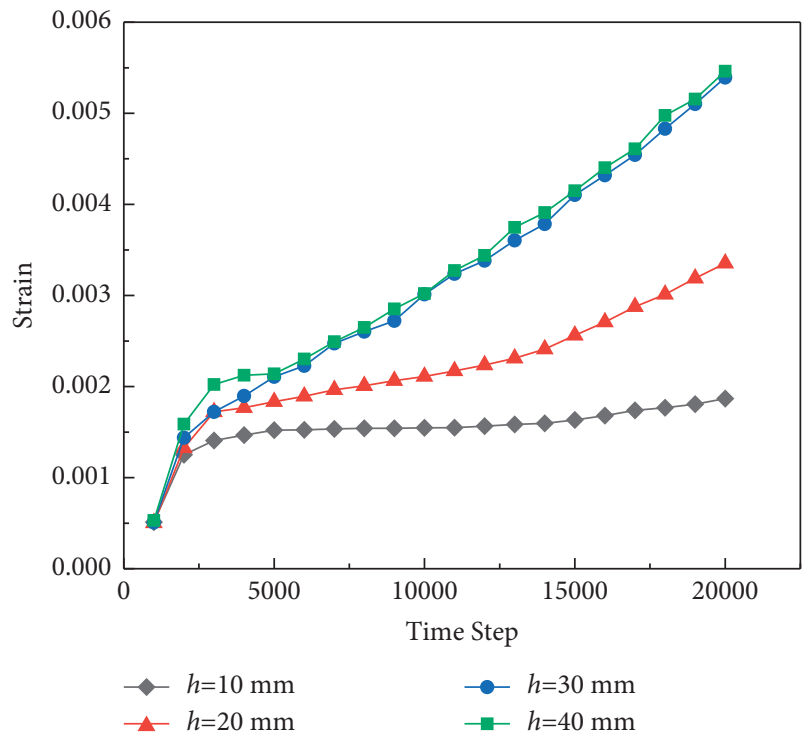

Figure 11: Creep curve of rock mass with different weak layer thickness.

$h=10 \mathrm{~mm}$ ). The influence law of rupture, the rupture mode, and equivalent displacement cloud diagram are shown in Figure 13.

Under constant load conditions, the cracks in the weak layer of the rock with one weak layer $(c=(1)$ are mainly shear cracks; and the rock tends to slide and fail along the rock. The displacement value of the left side of the upper

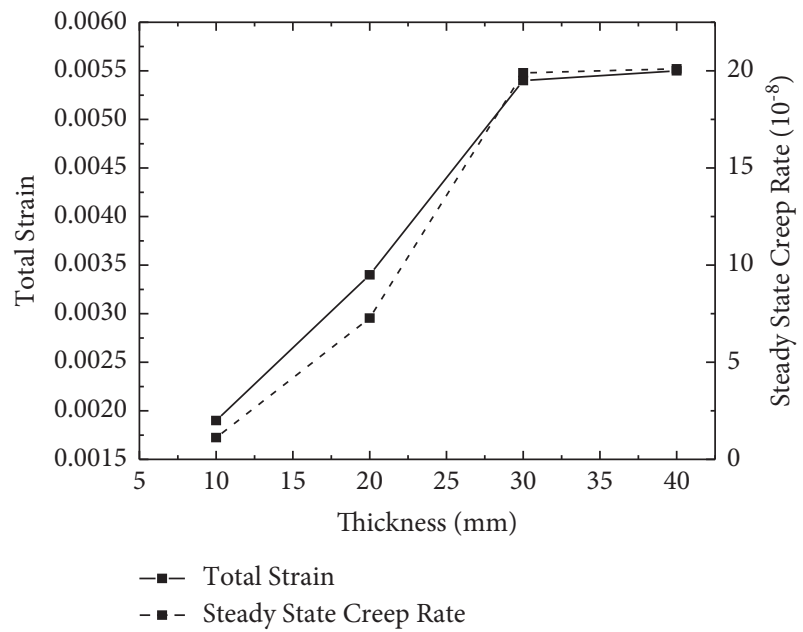

Figure 12: Total strain and steady creep rate of rock mass with different weak bed thicknesses.

interface of the lower weak layer in the rock mass with two weak layers $(c=(2)$ is about $0.001186 \mathrm{~mm}$. The displacement change is the largest. There is an obvious shear fracture surface near this spot, and the rock mass along the sliding shear failure is on the fractured surface of the rock mass. The cracks in the rock mass with three weak layers ( $c=(3)$ penetrate the weak interlayer, and the displacement value on the left side of the upper interface of the middle weak layer is $0.001613 \mathrm{~mm}$, which is the largest value; thus, a local shear fracture surface is generated at the middle 


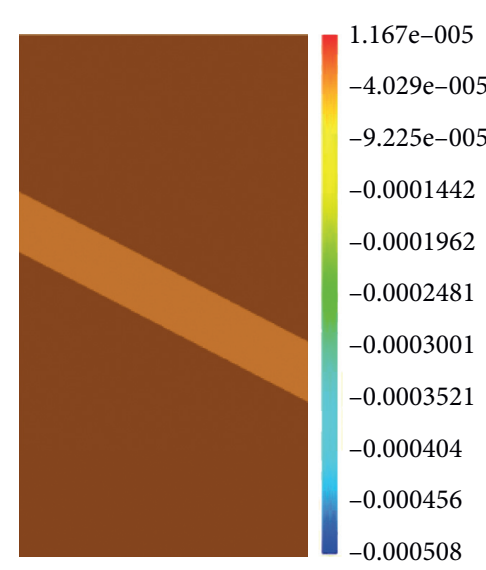

(a)
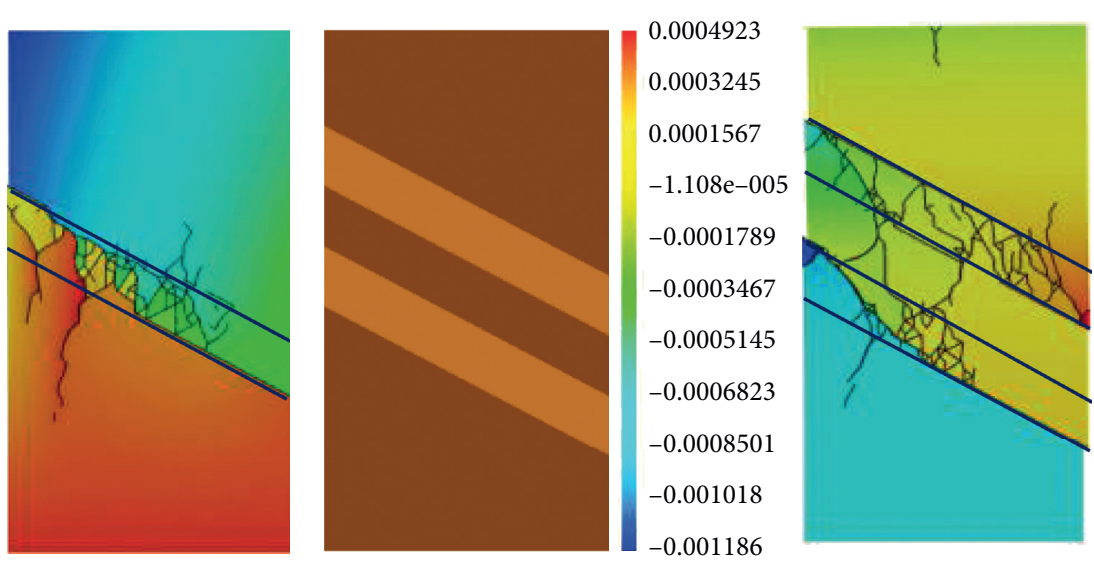

(b)
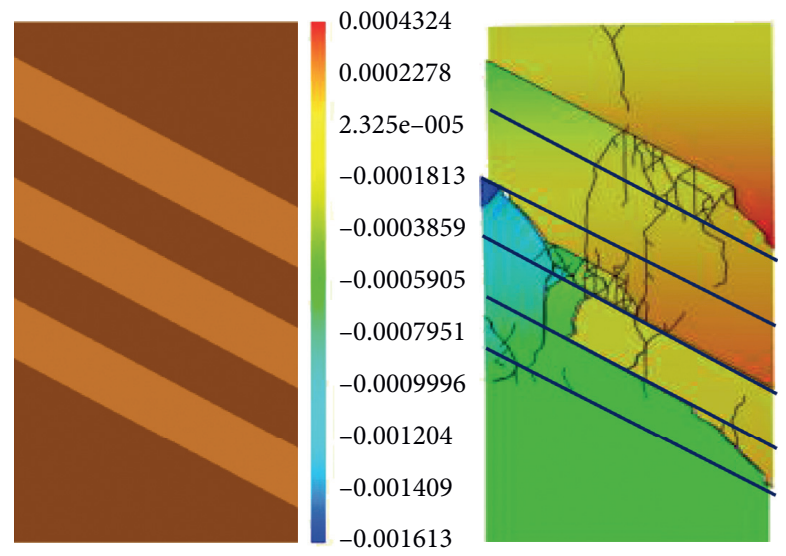

(c)

FIGURE 13: Rock mass with different weak layers and equivalent displacement nephogram. (a) $c=1$. (b) $c=2$. (c) $c=3$.

weak layer. The bearing capacity of the rock mass decreases, and the rock mass slips and fails along the shear plane. As the number of interlayers increases, the form of creep failure of the rock mass with weak layers changes from sliding shear failure along the weak layer to sliding shear failure through the weak interlayer.

Figure 14 shows the creep curves of rock masses with different numbers of weak layers. The comparative analysis shows that when the number of weak layers is $c=1$, the rock mass mainly presents a decelerating creep stage in which the creep rate gradually decreases with time. The characteristics of the constant velocity creep phase remain approximately constant with the creep rate. When the number of weak layers is $c=2$ or 3 , the rock mass presents a complete threestage creep process. Figure 14 shows that the steady-state creep rate $v_{c p}$ of each group of rock masses $(c=1,2,3)$ is $3.35 \times 10^{-8}, 5.86 \times 10^{-8}$, and $6.19 \times 10^{-8}$, respectively, and the total strain $\varepsilon$ is $0.00162,0.00302$, and 0.00345 , respectively. For rock masses with different weak layers, the total amount of instantaneous strain and creep under the same stress level is different, and both increase as the number of layers increases. According to Figure 15, the total strain and steadystate creep rate of the rock mass with weak layers increase as the number of weak layers increases. This is because of the increase in weak interlayers: the larger the volume of soft

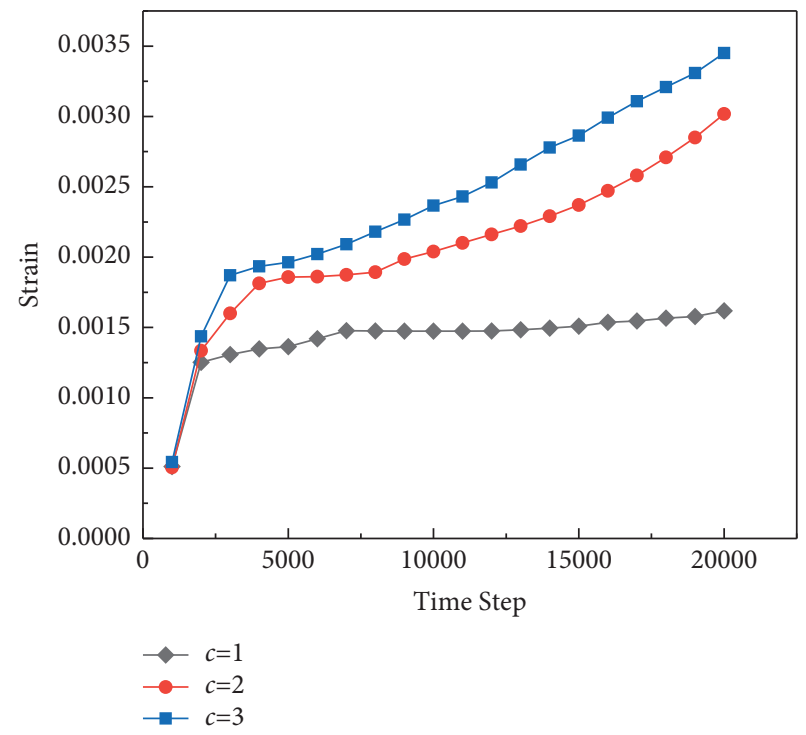

FIGURE 14: Creep curves of rock masses with different weak layers.

rock in the rock mass with weak layers is, the lower the overall rigidity of the rock mass will be, the greater the increase in plastic deformation will be, and the more likely it is that the rock mass will be broken. The numerical 


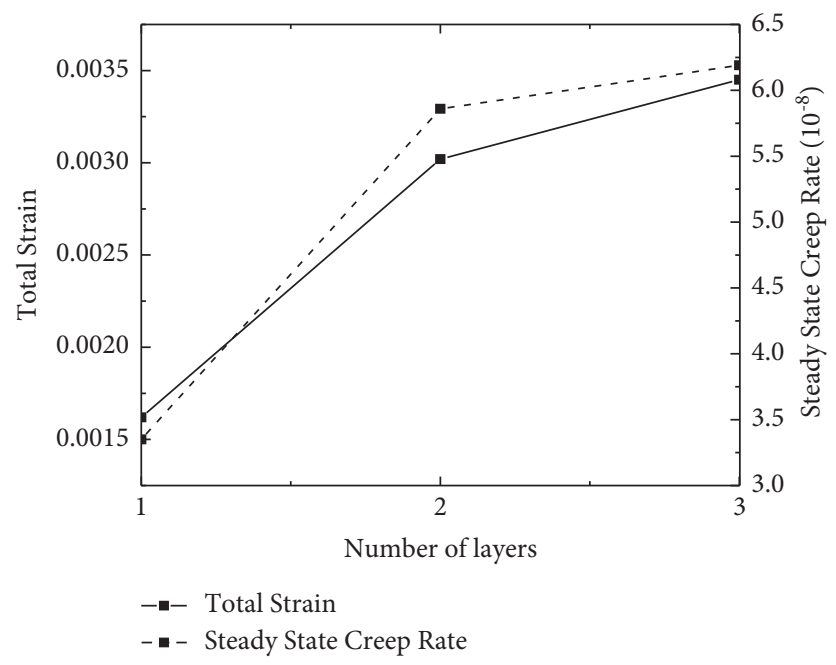

FIGURE 15: Total strain and steady creep rate of rock mass with different weak layers.

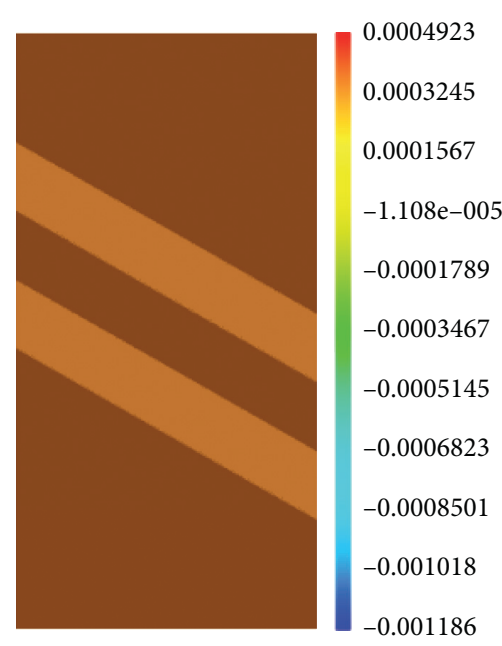

(a)

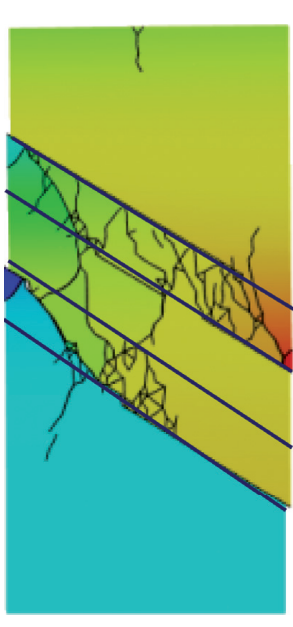

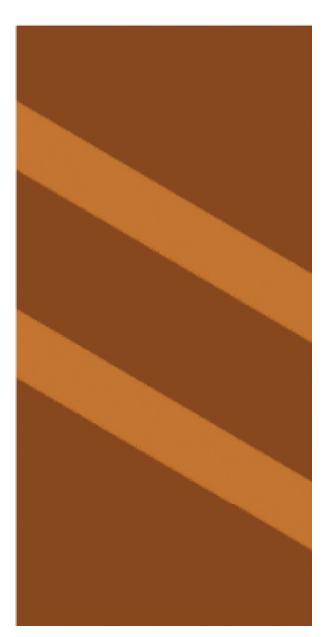

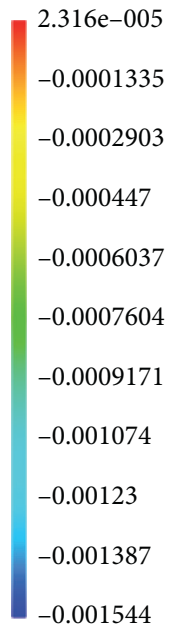

(b)
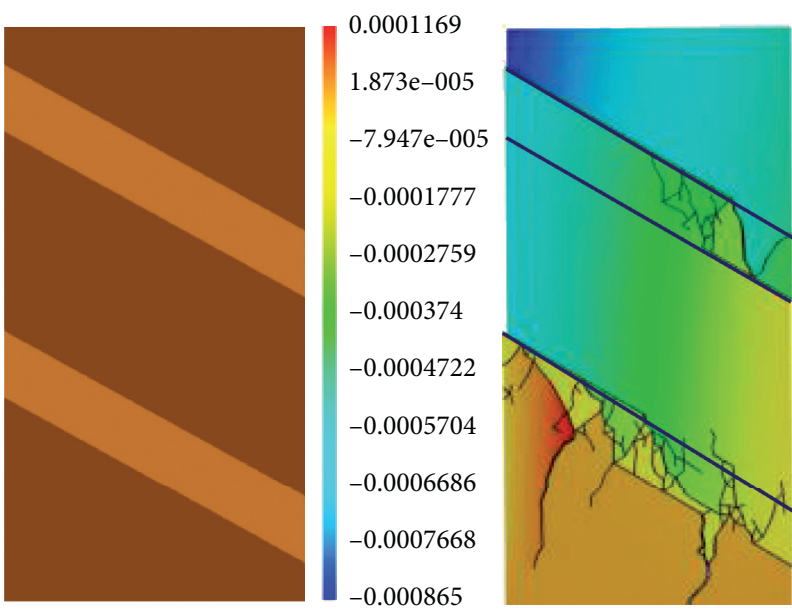

(c)

FIGURE 16: Rock mass with different weak layer spacing and equivalent displacement nephogram. (a) $d=10 \mathrm{~mm}$. (b) $d=20 \mathrm{~mm}$. (c) $d=30 \mathrm{~mm}$. 
simulation result is the same as the simulation result from the literature [33].

4.5. Influence of Weak Layer Spacing on Creep Characteristics of Rock Mass. Considering the influence of the distance between weak layers on the creep failure of a rock mass with double weak layers under a constant load, keep other conditions unchanged $\left(\theta=30^{\circ}, h=10 \mathrm{~mm}, c=1\right)$, and take $d=10,20$, and $30 \mathrm{~mm}$ for the distance between weak layers. The three groups of rock samples with double weak layers were numerically simulated, and the simulation results are shown in Figure 16.

Under the given working conditions, the creep rupture mode of the rock mass with the weak layer spacing $(d=10 \mathrm{~mm})$ is shown in this figure. The displacement value on the left side of the upper interface of the lower weak layer is about $0.001186 \mathrm{~mm}$, and the displacement change is the largest. There is an obvious shear fracture surface near this point, and the rock mass has sliding shear failure along the fracture surface. The displacement of the left unit at the upper end of the weak layer spacing $(d=20 \mathrm{~mm})$ shows the largest change, with a value of 0.001544 ; and the upper rock mass of the lower weak layer moves downward as a whole and slips along the shear fracture surface of the destroyed lower weak layer. The rock mass with the weak layer spacing $(d=30 \mathrm{~mm})$ also has the largest displacement on the left side of the upper end. When the calculation is completed, it is clear that the cracks in the lower weak layer do not intersect each other to form a through-plane, so there is no creep failure overall. The existence of a weak interlayer destroys the integrity of the rock mass. Under the long-term action of the load, cracks first occur at the weak layer. As time passes, the cracks gradually expand, connect, and penetrate the weak interlayer, forming a macroscopic shear. The fracture surface and the crack propagation speed at the hard rock are lower than those at the soft rock. Therefore, when the distance between the weak layers is larger, the time required for the crack to expand and connect at the hard rock in the two weak layers is longer; and the cracks at the two interlayers are more difficult to penetrate. Therefore, the larger the distance between the weak layers is, the less likely it is to undergo creep instability failure.

Figure 17 shows the creep curve with different weak layer spacing. Under the same stress level, when the weak layer spacing is $d=10 \mathrm{~mm}$, the instantaneous strain of the weak layer rock mass is $1.34 \times 10^{-4}$, the steady-state creep rate $v_{c p}$ is $5.8 \times 10^{-8}$, and the creep strain is 0.00358 . When the distance between weak layers is $d=20 \mathrm{~mm}$, the instantaneous strain of the rock mass with weak layers is $1.32 \times 10^{-4}$, the steady-state creep rate $v_{c p}$ is $2.8 \times 10^{-8}$, and the total strain $\varepsilon$ is 0.00238 . When the distance between weak layers is $d=30 \mathrm{~mm}$, the instantaneous strain of the rock mass with weak layers is $1.89 \times 10^{-4}$, the steady-state creep rate $v_{c p}$ is $1.6 \times 10^{-8}$, and the total strain $\varepsilon$ is 0.00161 . As shown in Figure 18, the creep strain and steady-state creep rate of the rock mass with weak layers decrease with the increase in the interlayer spacing; and the change rule of the instantaneous strain is not obvious.

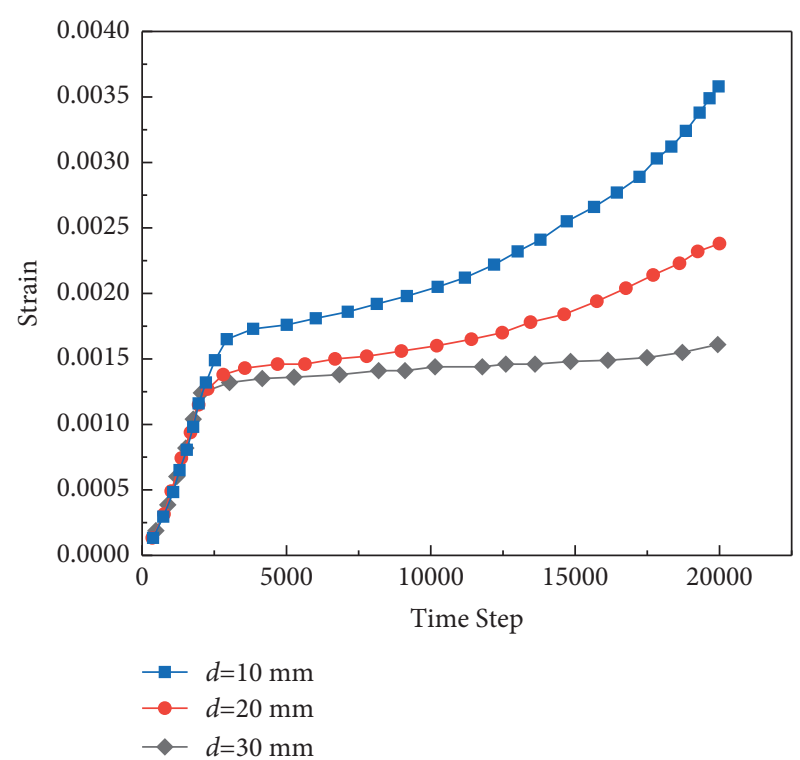

FIGURE 17: Creep curve of rock mass with different weak layer spacing.

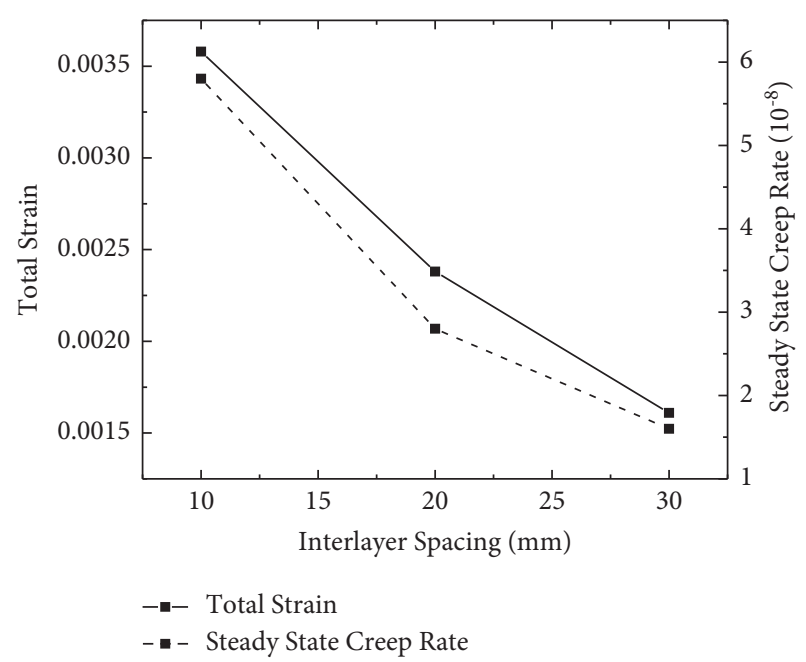

FIgURE 18: Total strain and steady creep rate of rock mass with different weak layer spacing.

\section{Conclusion}

This article mainly describes the evolution process of local element deformation and failure combined with the CDEM method, and it numerically simulates the influence of different weak layer inclinations, thicknesses, numbers of layers, and layer spacing on the creep characteristics of rock mass under the conditions of the uniaxial compression creep test. The conclusions are as follows:

(1) In CDEM, when calculating the interface failure, the judgment standard for the interface failure is based on the maximum tensile stress and the Mohr-Coulomb composite criterion. The failure modes are divided into tensile failure and shear failure. 
(2) With the increase in the dip angle of the weak layer, its creep failure mode changes from shear failure through the weak layer to slip shear failure along the weak layer. When the dip angle is within a certain range, as the dip angle of the weak layer increases, the total strain and steady-state creep rate of the rock mass decrease. After exceeding the threshold, the total strain and steady-state creep rate increase with the dip angle of the weak layer, showing a U-shaped distribution.

(3) Under long-term load, regardless of the thickness, the creep failure mode of the rock mass with weak layers always occurs along the fracture surface; as the thickness of the weak layer increases, the total strain of the rock mass with weak layers increases. The steady-state creep rate also increases.

(4) As the number of interlayers increases, the form of creep failure changes from sliding shear failure along the weak layer to sliding shear failure through the weak interlayer. The total strain and steady-state creep rate increase with the number of weak layers. This is because of the increase in weak interlayers. The volume of soft rock in the weak layered rock mass increases, the overall rigidity of the rock mass decreases, the plastic deformation increases, and the rock mass is more prone to damage.

(5) The distance between the weak interlayers affects the crack propagation speed during the creep process: The larger the interlayer spacing, the slower the crack propagation speed. The steady-state creep rate and total strain gradually decrease, and creep failure occurs along the shear fracture surface.

\section{Data Availability}

The data used to support the findings of this study are included within the article.

\section{Conflicts of Interest}

The authors declare that they have no conflicts of interest.

\section{Acknowledgments}

The financial support from the National Key Research and Development Plan (2017YFC1503101), Liaoning Province Key Science and Technology Innovation Base Joint Open Fund Project (2020-KF-13-06), and Project funded by the Education Department of Liaoning Province (LJ2020JCL013) are gratefully acknowledged.

\section{References}

[1] R. S. Yang, W. Y. Li, and S. Z. Fang, "Experimental study on impact dynamic characteristics of layered composite rocks," Chinese Journal of Rock Mechanics and Engineering, vol. 38, no. 09, pp. 1747-1757, 2019, (in chinese).

[2] A. Li, G. J. Shao, and J. B. Su, "Uniaxial compression test and numerical simulation for alternatively soft and hard interbedded rock mass[J]," Journal of Hohai University (Natural Sciences), vol. 46, no. 06, pp. 533-538, 2018, (in chinese).

[3] Q. Q. Xu, Q. L. Gao, and J. M. Wu, "Study on mechanical properties of weak interlayers containing thin layer hard rock [J]," Chinese Journal of Underground Space and Engineering, vol. 15, no. S2, pp. 548-554, 2019, (in chinese).

[4] L. C. Li, T. Xu, and C. A. Tang, "Numerical simulation of creep induced progressive failure process of rock under uniaxial compression[J]," Rock and Soil Mechanics, vol. 28, no. 09, pp. 1978-1982+1986, 2007, (in chinese).

[5] M.-y. Ren, Q.-y. Zhang, S.-y. Chen, L.-y. Zhang, Y.-y. Jiao, and W. Xiang, "Experimental study on mechanical properties of anchored rock-like material with weak interlayer under uniaxial compression," Geotechnical \& Geological Engineering, vol. 38, no. 5, pp. 4545-4556, 2020.

[6] H. F. Deng, W. Wang, and J. L. Li, "Experimental study on anisotropic characteristics of bedded sandstone[J]," Chinese Journal of Rock Mechanics and Engineering, vol. 37, no. 01, pp. 112-120, 2018, (in chinese).

[7] R. G. Deng and X. M. Fu, "On the simulative experimental study of mechanical properties of stratified rock mass[J]," Journal of Experimental Mechanics, vol. 12, 2015, (in chinese).

[8] X. D. Fu, J. Z. Lu, B. Huang et al., "Experimental study on strength and failure mode of strongly weathered mudstone with weak interlayer[J]," Journal of Southeast University (Natural Science Edition), vol. 51, no. 02, pp. 242-248, 2021, (in chinese).

[9] X. Chen, Z. Zhang, D. Q. Li et al., "Study on the influence of weak interlayer on uniaxial compression behaviors of cement soils[J]," Chinese Journal of Rock Mechanics and Engineering, vol. 39, no. 02, pp. 398-412, 2020, (in chinese).

[10] S. Y. Zuo, W. B. Shi, F. Liang et al., "Numerical simulation and engineering application for failure modes and criterion of layered anisotropic rock mass[J]," Chinese Journal of Geotechnical Engineering, vol. 37, no. S1, pp. 191-196, 2015, (in chinese).

[11] N. Yao, Y. C. Ye, Q. H. Wang et al., "Particle flow code numerical simulation of uniaxial compression mechanical behavior of gently inclined layered rock[J]," Journal of Engineering Geology, vol. 26, no. 04, pp. 835-843, 2018, (in chinese).

[12] L. Xie, P. Jin, T.-C. Su, X. Li, and Z. Liang, "Numerical simulation of uniaxial compression tests on layered rock specimens using the discrete element method," Computational Particle Mechanics, vol. 7, no. 4, pp. 753-762, 2020.

[13] O. C. Zienkiewicz and G. N. Pande, "Time-dependent multilaminate model of rocks: a numerical study of deformation and failure of rock mass [J]," International Journal for $\mathrm{Nu}$ merical and Analytical Methods in Geomechanics, vol. 1, no. 3, pp. 219-247, 1977.

[14] J. C. Jaeger, "Shear failure of anistropic rocks," Geological Magazine, vol. 97, no. 1, pp. 65-72, 1960, [24].

[15] J. C. Jaeger, "Friction of rocks and stability of rock slopes," Géotechnique, vol. 21, no. 2, pp. 97-134, 1971.

[16] H. Saroglou and G. Tsiambaos, "A modified Hoek-Brown failure criterion for anisotropic intact rock," International Journal of Rock Mechanics and Mining Sciences, vol. 45, no. 2, pp. 223-234, 2008.

[17] M. Singh and B. Singh, "Modified Mohr-Coulomb criterion for non-linear triaxial and polyaxial strength of jointed rocks," International Journal of Rock Mechanics and Mining Sciences, vol. 51, no. 2, pp. 43-52, 2012.

[18] Z.-L. Chen, X. Hu, and Q. Xu, "Experimental study of motion characteristics of rock slopes with weak intercalation under 
seismic excitation," Journal of Mountain Science, vol. 13, no. 3, pp. 546-556, 2016.

[19] Q. X. Huang and H. M. Hu, "Experimental study of simulation material and matching for whole stress and strain process of clay aquiclude [J]," Journal of Mining \& Safety Engineering, vol. 34, no. 06, pp. 1174-1178, 2017, (in chinese).

[20] L. Xia, J. S. Yao, and L. Jiang, "Sample preparation method of layered rock and uniaxial compression mechanics mechanism [J]," Journal of Water Resources and Architectural Engineering, vol. 17 , no. 06, pp. 70-76+98, 2019, (in chinese).

[21] C. F. Xiao, X. Lin, and G. Wu, "The effect of the bond strength between layers on compressive mechanical properties of the composite rock [J]," Journal of Chongqing University, vol. 11, no. 1 , pp. 120-126, 1988, (in chinese).

[22] W. Y. Xu, W. Huang, and T. Zhang, "Experimental study on rheological properties of layered rock mass with soft interlayers [J]," Journal of Hohai University(Natural Sciences), vol. 48, no. 04, pp. 327-333, 2020, (in chinese).

[23] L. X. Xiong, Z. Y. Xu, T. B. Li, and Y. Zhang, "Bonded-particle discrete element modeling of mechanical behaviors of interlayered rock mass under loading and unloading conditions," Geomechanics and Geophysics for Geo-Energy and GeoResources, vol. 5, no. 1, pp. 1-16, 2019.

[24] Y. P. Li, J. Liu, and C. H. Yang, "Influence of mudstone interlayer on deformation and failure characteristics of salt rock[J]," Chinese Journal of Rock Mechanics and Engineering, vol. 25, no. 12, pp. 2461-2466, 2006, (in chinese).

[25] F. Huang, H. Zhu, Q. Xu, Y. Cai, and X. Zhuang, "The effect of weak interlayer on the failure pattern of rock mass around tunnel-Scaled model tests and numerical analysis," Tunnelling and Underground Space Technology, vol. 35, pp. 207-218, 2015.

[26] H. Haeri, "Experimental crack analyses of concrete-like CSCBD specimens using a higher order DDM," Computers and Concrete, vol. 16, no. 6, pp. 881-896, 2015.

[27] H. Haeri, "Simulating the crack propagation mechanism of pre-cracked concrete specimens under shear loading conditions," Strength of Materials, vol. 47, no. 4, pp. 618-632, 2015.

[28] V. Sarfarazi, H. Haeri, A. B. Shemirani, and Z. Zhu, "Shear behavior of non-persistent joint under high normal load," Strength of Materials, vol. 49, no. 2, pp. 320-334, 2017.

[29] H. Haeri, V. Sarfarazi, M. Yazdani, A. B. Shemirani, and A. Hedayat, "Experimental and numerical investigation of the center-cracked horseshoe disk method for determining the mode I fracture toughness of rock-like material," Rock Mechanics and Rock Engineering, vol. 51, no. 1, pp. 173-185, 2018.

[30] M. J. Jiang, N. Zhang, Z. F. Shen, and H. Chen, "DEM analyses of crack propagation in flawed rock mass under uniaxial compression [J]," Rock and Soil Mechanics, vol. 36, no. 11, pp. 3293-3300+3314, 2015, (in chinese).

[31] P. Xu and S. Q. Yang, "Numerical analysis of creep mechanical property for bedded composite rock," Journal of Mining \& Safety Engineering, vol. 35, no. 01, pp. 179-187, 2018, (in chinese).

[32] Y. B. Zhang, Y. D. Xu, and X. X. Liu, "Quantitative characterization of three-dimensional rock fractures and mesoscopic study of propagation and evolution based on CT [J]," Rock and Soil Mechanics, vol. 42, no. 10, pp. 1-13, 2021, (in chinese).

[33] T. T. Hu, Z. B. Kang, and J. X. Chen, "Simulation study on mechanical behavior of carbonaceous slate with weak interlayer under uniaxial compression [J]," Chinese Journal of Applied Mechanics, vol. 38, no. 04, pp. 1580-1587, 2021, (in chinese). 